\title{
Human $\gamma \delta$ T-Cell Control of Mucosal Immunity and Inflammation
}

\author{
Neil E. McCarthy ${ }^{1 *}$ and Matthias Eberl ${ }^{2}$
}

${ }^{1}$ Centre for Immunobiology, Bart's and The London School of Medicine and Dentistry, The Blizard Institute, Queen Mary University of London, London, United Kingdom, ${ }^{2}$ Division of Infection and Immunity, School of Medicine, Systems Immunity Research Institute, Cardiff University, Cardiff, United Kingdom

Human $\gamma \delta$ T-cells include some of the most common "antigen-specific" cell types in peripheral blood and are enriched yet further at mucosal barrier sites where microbial infection and tumors often originate. While the $\gamma \delta$ T-cell compartment includes multiple subsets with highly flexible effector functions, human mucosal tissues are dominated by host stress-responsive $\mathrm{V} \delta 1^{+} \mathrm{T}$-cells and microbe-responsive $\mathrm{V} \delta 2^{+} \mathrm{T}$-cells. Widely recognized for their potent cytotoxicity, emerging data suggest that $\gamma \delta$ T-cells also exert strong influences on downstream adaptive immunity to pathogens and tumors, in particular via activation of antigen-presenting cells and/or direct stimulation of other mucosal leukocytes. These unique functional attributes and lack of $\mathrm{MHC}$ restriction have prompted considerable interest in therapeutic targeting of $\gamma \delta$ T-cells. Indeed, several drugs already in clinical use, including vedolizumab, infliximab, and azathioprine, likely owe their efficacy in part to modulation of $\gamma \delta$ T-cell function. Recent clinical trials of V82 ${ }^{+} \mathrm{T}$-cell-selective treatments indicate a good safety profile in human patients, and efficacy is set to increase as more potent/targeted drugs continue to be developed. Key advances will include identifying methods of directing $\gamma \delta$ T-cell recruitment to specific tissues to enhance host protection against invading pathogens, or alternatively, retaining these cells in the circulation to limit peripheral inflammation and/or improve responses to blood malignancies. Human $\gamma \delta$ T-cell control of mucosal immunity is likely exerted via multiple mechanisms that induce diverse responses in other types of tissue-resident leukocytes. Understanding the microenvironmental signals that regulate these functions will be critical to the development of new $\gamma \delta$ T-cell-based therapies.

Keywords: human, mucosal, gammadelta T-cells, Vdelta1, Vdelta2

\section{INTRODUCTION}

The $\gamma \delta$ T-cell compartment includes some of the most numerous "antigen-specific" cell types in peripheral blood and is enriched yet further in mucosal tissues including the lung and intestine $(1,2)$. In humans, $\gamma \delta$ T-cells are typically divided into distinct subsets based on $\delta$-chain usage, each being specialized to detect a different class of common antigen or host molecule generated by microbial infection, stress, and/or malignant transformation. Pathobionts frequently invade the body via epithelial barriers, which are also major sites of tumorigenesis, hence $\gamma \delta$ T-cell function in mucosal tissues represents a critical component of host protection against a range of major diseases. While the ability of human $\gamma \delta$ T-cells to lyse infected or transformed host cells has been well documented, less is known about their influence on downstream antimicrobial immunity and mucosal inflammation, 
which must be carefully regulated in order to prevent autoimmune pathology, tissue damage, and cancer. Indeed, a recent analysis of tumor transcriptome data identified $\gamma \delta$ T-cell infiltration as the best prognostic marker of survival (1), indicating that $\gamma \delta$ T-cell responses can significantly influence clinical outcomes in human patients, but the mucosal functions of these cells and their impact on barrier protection remain poorly understood. This mini-review focuses on the potential roles of $\gamma \delta$ T-cells in human mucosal tissues, with an emphasis on their ability to influence conventional leukocyte responses at these sites. We consider that $\gamma \delta$ T-cell detection of stress molecules and microbial signals can significantly alter adaptive immunity and inflammation at mucosal barrier sites, consistent with the increasing recognition that tissue-resident T-cells play essential roles in human immunity. Where useful context has been drawn from studies performed in animal models, the non-human origins of these data have been clearly indicated.

\section{$\gamma \delta$ T-CELLS MEDIATE EPITHELIAL BARRIER PROTECTION}

Epithelial cells are exposed to a variety of microbial and environmental signals that induce distinct patterns of cytokine and chemokine secretion, as well as rapid changes in cell surface expression of host stress molecules. Acting in concert, these factors can stimulate a range of leukocyte responses as complex as those imparted by myeloid antigen-presenting cells (3). Innatelike lymphocytes residing in the epithelial layer and underlying mucosa are key responders to these barrier stress signals, and $\gamma \delta$ T-cells comprise a major component of this "unconventional" lymphocyte pool. It is well-established that epithelial signaling to $\gamma \delta$ T-cells begins early, in the thymus, where these cells are imparted with greater gut-homing potential (integrin $\alpha 4 \beta 7$ expression) than conventional lymphocytes, and exhibit more efficient proliferation upon subsequent recruitment to the murine mucosa (4). Less clear is how far epithelial cells continue to shape $\gamma \delta$ T-cell function upon their arrival in mucosal tissues, although an intimate functional relationship controlled by a variety of different signals seems increasingly likely (5). Indeed, the $\gamma \delta \mathrm{T}$-cell repertoire in human intestine undergoes major changes with age and becomes oligoclonal in adults (6), suggesting strong local selection by site-specific signals that include host butyrophilinlike molecules $(5,7)$, dietary and microbial ligands for the aryl hydrocarbon receptor (8), and common pathogen products and stress antigens. Accordingly, studies in parabiotic mice have demonstrated that the frequency of $\gamma \delta$ T-cell mixing between animals is low in the gut epithelium, whereas up to $50 \%$ cell exchange between animals can be observed in the lamina propria (9). These data suggest that $\mathrm{V} \delta 1^{+}$intraepithelial lymphocytes $(\gamma \delta$-IEL) may develop in situ, whereas lamina propria $\gamma \delta$ T-cells depend both on recruitment from the peripheral blood and local proliferation in order to maintain the local pool. In mice, it is widely accepted that the majority of $\gamma \delta$ T-cells are pre-programmed with cytokine potential and effector functions within the thymus (10). However, recent data suggest that $\gamma \delta$ T-cell function outside the thymus is more plastic than originally thought (11), and the murine ${\mathrm{V} \gamma 7^{+}}^{+}$ subset appears to require Btnl1 expression by the gut epithelium to develop IFN $\gamma$-expressing capacity (5). In humans, the closely related proteins BTNL3 and BTNL8 may similarly cooperate to promote colonic expansion of the analogous $\mathrm{V} \gamma 4^{+}$subset (5), although the functional impact of this mechanism remains unclear, and populations expressing alternative $\gamma$-chains also reside in this tissue. Nonetheless, human $\gamma \delta \mathrm{T}$-cell function does not appear to be "hard-wired" in the thymus and remains receptive to site-specific cues that likely induce distinct functional profiles in different tissues and organs. Intriguingly, BTNL2 is primarily expressed in the small intestinal epithelium and appears to function as a negative regulator of T-cell activation (12), with mutations in this protein conferring increased risk of inflammatory bowel disease (IBD) (13). It is possible, therefore, that therapeutic strategies targeting BTNL molecules and/or $\gamma \delta \mathrm{T}$-cell activation in the human gut may yield new treatment options for patients with IBD.

Consistent with a role for $\gamma \delta$-IEL in monitoring gut barrier function, recent data indicate that these cells are highly motile in the mouse intestine and actively scan the epithelium for signs of cellular stress, with pro-inflammatory cytokines and/or pathogen encounter significantly modulating this behavior $(14,15)$. Indeed, while $\gamma \delta$-IEL numbers appear largely unaffected in germ-free mice (16), epithelial cell contact with gut bacteria can induce $\gamma \delta$-IEL expression of antimicrobial peptides (17), confirming that exposure to the microbiota can significantly alter their function. It is likely that human gut $\gamma \delta$-IELs scan the epithelium for expression of MHC I-related genes MICA and MICB, which function as stress-inducible triggers for $\gamma \delta \mathrm{T}$-cell cytotoxicity $(18,19)$. MICA/B expression has already been identified in carcinomas of the lung and colon, where these molecules are associated with enhanced tumor infiltration by cytotoxic $\gamma \delta$ T-cells (20). Accordingly, $\gamma \delta$ T-cells isolated from human lung tumors can selectively lyse autologous malignant cells ex vivo (21). $V \delta 1^{+} \gamma \delta \mathrm{T}$-cells also seem to be expanded in many transplant recipients, where they express gut-homing receptors and are strongly activated by intestinal tumor cells but not healthy epithelial cell lines (22).

$\mathrm{MICA} / \mathrm{B}$ is recognized with high affinity by the natural killer (NK) cell receptor NKG2D (23), which is expressed by human $\gamma \delta$-IELs under the control of IL-15 (24). This cytokine appears to play an important role in steady-state maintenance of the murine $\gamma \delta$-IEL compartment (25), and thymic expression of IL-15 is required to modulate histone acetylation of the $V \gamma 5$ gene segment, which is preferentially used by mouse gut $\gamma \delta$-IELs (26). Consistent with these data is the observation that epithelial supply of IL-15 cytokine plays a crucial role in $\gamma \delta$ T-cell control of mucosal inflammation in murine colitis (27). Similarly, human intestinal $\mathrm{V} \delta 1^{+}$ T-cells are significantly expanded in both celiac disease and IBD $(28,29)$, which are characterized by high mucosal levels of the tissue damage-associated cytokine IL-15 (30-32). Intriguingly, patients with celiac disease exhibit upregulated activity of cytotoxic lymphocytes (24), but a subset of NKG2A $\mathrm{A}^{+} \gamma \delta$ T-cells can reportedly decrease IFN $\gamma$ expression by cocultured gut $\alpha \beta$ T-cells (33). Similarly, transfer of $\gamma \delta$-IELs into mice that lack these cells can protect against chemical colitis by decreasing host lymphocyte expression of pro-inflammatory cytokines and modulating epithelial production of IL-15 (27). These data strongly suggest that $\gamma \delta$-IELs help maintain the integrity of the epithelium by altering 
the local activity of other gut leukocyte subsets, and that IL-15 may alert these cells to tissue stress, including the need to remove infected/malignant epithelial cells from the barrier. Consequently, when intestinal $\gamma \delta$ T-cells are deleted in murine models, the gut epithelium displays uncontrolled IFN $\gamma$ expression, chronic inflammation, and impaired barrier regeneration (34).

$\mathrm{V} \delta 1^{+} \mathrm{T}$-cell influences on other leukocyte populations have previously been reported in various settings of relevance to mucosal barrier protection. For example, maturation of $\mathrm{CD} \mathrm{c}^{+}$ myeloid dendritic cells (DC) can be induced by direct contact with CD1c-restricted $\mathrm{V} \delta 1^{+} \mathrm{T}$-cells in vitro (35), suggesting that similar interactions may also occur at mucosal sites in vivo. The resultant mature, $\mathrm{CD} 1 \mathrm{c}^{+} \mathrm{DC}$ are endocytic, can efficiently present novel protein antigens, and are more potent stimulators of naïve T-cell proliferation than DC activated with cytokines alone. Intriguingly, these characteristics can also be observed in human lung DC isolated from patients with atopic asthma and may represent genuine features of mucosal inflammatory disorders (36). $\mathrm{V} \delta 1^{+} \mathrm{T}$-cell-induced maturation of $\mathrm{CD}^{+}$myeloid $\mathrm{DC}$ does not rely on foreign antigen and is chiefly mediated by $\mathrm{TNF} \alpha(35)$, which also triggers rapid activation of $\gamma \delta$ T-cells (37-39), and likely enables timely immune responses to a barrier breach. Indeed, full DC maturation has long been known to require interaction with T-cells (40), but $\alpha \beta$ T-cell clones with fine antigen specificity are rare in the periphery. Tissue-resident $\gamma \delta$ T-cells may therefore accelerate DC maturation in the mucosa by relying on nonpolymorphic molecules to mediate this interaction (41). Indeed, increased CD1 expression by APC has already been reported to enhance T-cell stimulation in a murine model (42). It is also important to note that this model does not preclude a role for the microbiota, since microbial antigen can enhance APC presentation of self-antigens to CD1-restricted T-cells (43). Indeed, CD1 ${ }^{+}$ DC can also present pollen-derived lipid antigens to $\mathrm{V} \delta 1^{+} \mathrm{T}$-cells derived from the blood of allergic donors (44), suggesting that similar interactions can also occur in the human lung in allergic asthma. While it is unclear to what extent laboratory mice can accurately model asthma pathology (45), previous studies have observed a major influence of lung $\gamma \delta$ T-cells on allergen-induced airway hyperreactivity and excess production of $\operatorname{IgE}(46,47)$, which are cardinal features of the human disease. Intriguingly, these effects were again associated with a shift in cytokine production by pulmonary $\alpha \beta$ T-cells, further suggesting that $\gamma \delta$ T-cells can exert complex effects via their influence on other mucosal leukocyte populations. Indeed, gut-tropic $\gamma \delta \mathrm{T}$-cells can promote Th1/Th17 differentiation of $\mathrm{CD}^{+}{ }^{+} \mathrm{T}$-cells in vivo to exacerbate colitis in murine models $(48,49)$, and a $\mathrm{V} \delta 2^{+}$subset expressing the PD1 isoform $\Delta 42$ promotes gut inflammation in humanized mice via putative effects on DC (50). Together, these data suggest that $\gamma \delta$ T-cells may exert similarly potent influences on adaptive immunity and inflammation in human mucosal tissues.

\section{$\gamma \delta$ T-CELLS STIMULATE COMPLEX MUCOSAL LEUKOCYTE RESPONSES}

Often referred to as rare cells, recent estimates suggest that the phosphoantigen-responsive $\mathrm{V} \delta 2^{+}$population in fact accounts for $\sim 1$ in 40 memory T-cells in healthy adults and may represent the single largest recall response in the human body $(2,51)$. Indeed, $\mathrm{V} \delta 2^{+} \mathrm{T}$-cells are capable of expanding yet further to dominate the blood lymphocyte pool in a wide range of infections $(52,53)$, which has led to extensive study of these cells in the circulation as well as the common misconception that they are restricted to the blood. However, several reports have now identified that the majority of blood V $\delta 2^{+} \mathrm{T}$-cells express homing receptors for epithelial barrier sites including the skin (CLA) and intestine (integrin $\alpha 4 \beta 7$ and CCR9) $(50,54,55)$. This tissue-tropic phenotype is consistent with the role of $\mathrm{V} \delta 2^{+} \mathrm{T}$-cells in host protection against pathogens that colonize epithelial barriers and produce the metabolite $(E)$ 4-hydroxy-3-methyl-but-2-enyl pyrophosphate (HMB-PP) (56). Indeed, while circulating $\mathrm{V} \delta 2^{+} \mathrm{T}$-cells are well situated to detect host cell accumulation of phosphoantigen in blood malignancies (57), the majority of non-hematological cancers are epithelial in origin, such that $\mathrm{V} \delta 2^{+} \mathrm{T}$-cell recruitment to these sites is likely to enhance tumor surveillance as well as antimicrobial immunity. $\mathrm{V} \delta 2^{+} \mathrm{T}$-cells express high levels of $\alpha 4 \beta 7$ in humans $(22,55,58)$, are rapidly recruited to mucosal tissues in higher primates in vivo $(59,60)$, and mediate effective host protection against bacteria in humanized mice (61). Recent work in a macaque model also demonstrated that injection of HMB-PP or related compounds stimulates $\mathrm{V} \delta 2^{+} \mathrm{T}$-cell expansion in the blood and accumulation of a CD $27^{+}$IFN $\gamma$-producing subset in the lungs (59). Intriguingly, lung accumulation of $\mathrm{V} \delta 2^{+} \mathrm{T}$-cells persisted for several months and was associated with a corresponding increase in $\mathrm{CD}^{+}$and $\mathrm{CD}^{+}$conventional $\mathrm{T}$-cell numbers, suggesting that activation of mucosal $\mathrm{V} \delta 2^{+} \mathrm{T}$-cells exerts multiple downstream effects on other leukocyte compartments. Indeed, $\mathrm{V} \delta 2^{+} \mathrm{T}$-cell activation in vivo has since been shown to enhance conventional Th1 responses in the lung and promote mucosal release of growth factors that confer protection against a range of different pathogens (including Listeria monocytogenes, Mycobacterium tuberculosis, and Yersinia pestis) $(60,62,63)$. Since HMB-PP injection into macaques promotes $\mathrm{V} \delta 2^{+} \mathrm{T}$-cell expansion and recruitment to the intestinal mucosa as well as the lung $(59,60)$, it is likely that these cells exert similar effects on $\alpha \beta$ T-cell responses and antimicrobial immunity in the primate gut. Consistent with this concept, human gut tissue contains $\mathrm{V} \delta 2^{+} \mathrm{T}$-cells that express the tissue-resident memory T-cell marker CD103, exhibit distinct patterns of cytokine production, and modify IFN $\gamma$ expression by autologous gut $\mathrm{CD}^{+} \mathrm{T}$-cells $(55,64)$. In mice, T-cell entry into the epithelium combined with local IL- 15 and TGF- $\beta$ signaling is required for the formation of long-lived memory cells that express CD103 (65). Whether or not $\mathrm{CD}_{103^{+}} \mathrm{V} \delta 2^{+} \mathrm{T}$-cells in human tissues represent a long-lived population with distinct roles in mucosal immunity is currently unclear.

We have previously demonstrated that activation of $\mathrm{V} \delta 2^{+}$ $\mathrm{T}$-cells in human intestine modulates cytokine production by colonic $\alpha \beta$ T-cells in the same piece of gut tissue (55), indicating that these cells are present in sufficient numbers to exert potent effects on downstream mucosal immunity. Moreover, like $\mathrm{V} \delta 1^{+}$ $\mathrm{T}$-cells the $\mathrm{V} \delta 2^{+}$population can promote generation of mature DC via a TNF-dependent mechanism $(66,67)$, illustrating a marked ability of these "innate-like" cells to trigger adaptive immune responses. In the case of the $\mathrm{V} \delta 2^{+}$subset, this process 
also confers potent APC capacity on the $\gamma \delta$ T-cells, likely allowing rapid amplification of immune responses at sites of barrier breach and microbial invasion. Early work in this area demonstrated that microbial activation induced human $\mathrm{V} \delta 2^{+} \mathrm{T}$-cells to process and present antigens as efficiently as DC, as well as provide costimulatory signals that stimulated naïve $\alpha \beta$ T-cell proliferation and differentiation $(68,69)$. It is now widely recognized that blood V $\delta 2^{+} \mathrm{T}$-cells can display remarkably flexible APC functions, while the nature of the $\alpha \beta$ T-cell responses they induce in tissues is likely directed by the stimuli encountered at specific anatomical sites. Indeed, "V $\delta 2-A P C "$ function appears to be optimally induced by microenvironmental signals known to be highly enriched in the human gut, namely microbe-derived HMB-PP (70), pro-inflammatory mediator TNF $\alpha$ (71), and epithelial cytokine IL-15 (32). It is perhaps unsurprising then that human intestinal V82-APC are efficient inducers of the barrier defense mediator IL-22 (72), whereas conventional myeloid APC in this tissue are instead specialized to induce "pro-symbiotic" IL-17 responses (73). Intriguingly, therapeutic antibody-mediated disruption of Th17 biology led to increased mucosal inflammation in patients with Crohn's disease during randomized controlled trials $(74,75)$, suggesting that $\mathrm{V} \delta 2^{+}$T-cell-directed immunotherapies might prove to be an effective method of enhancing barrier protection without impacting on mucosal levels of IL-17. Indeed, recruitment of circulating $\mathrm{V} \delta 2^{+} \mathrm{T}$-cells to inflamed skin lesions has already been identified in patients with psoriasis (54), and this population can also infiltrate the peritoneal cavity in patients with bacterial infections (39). In both cases, local V82 ${ }^{+}$ T-cell numbers and activation state were significantly correlated with therapeutic/patient outcomes, suggesting that these cells significantly impact on the clinical course of both inflammatory and infectious pathologies affecting multiple human tissues.

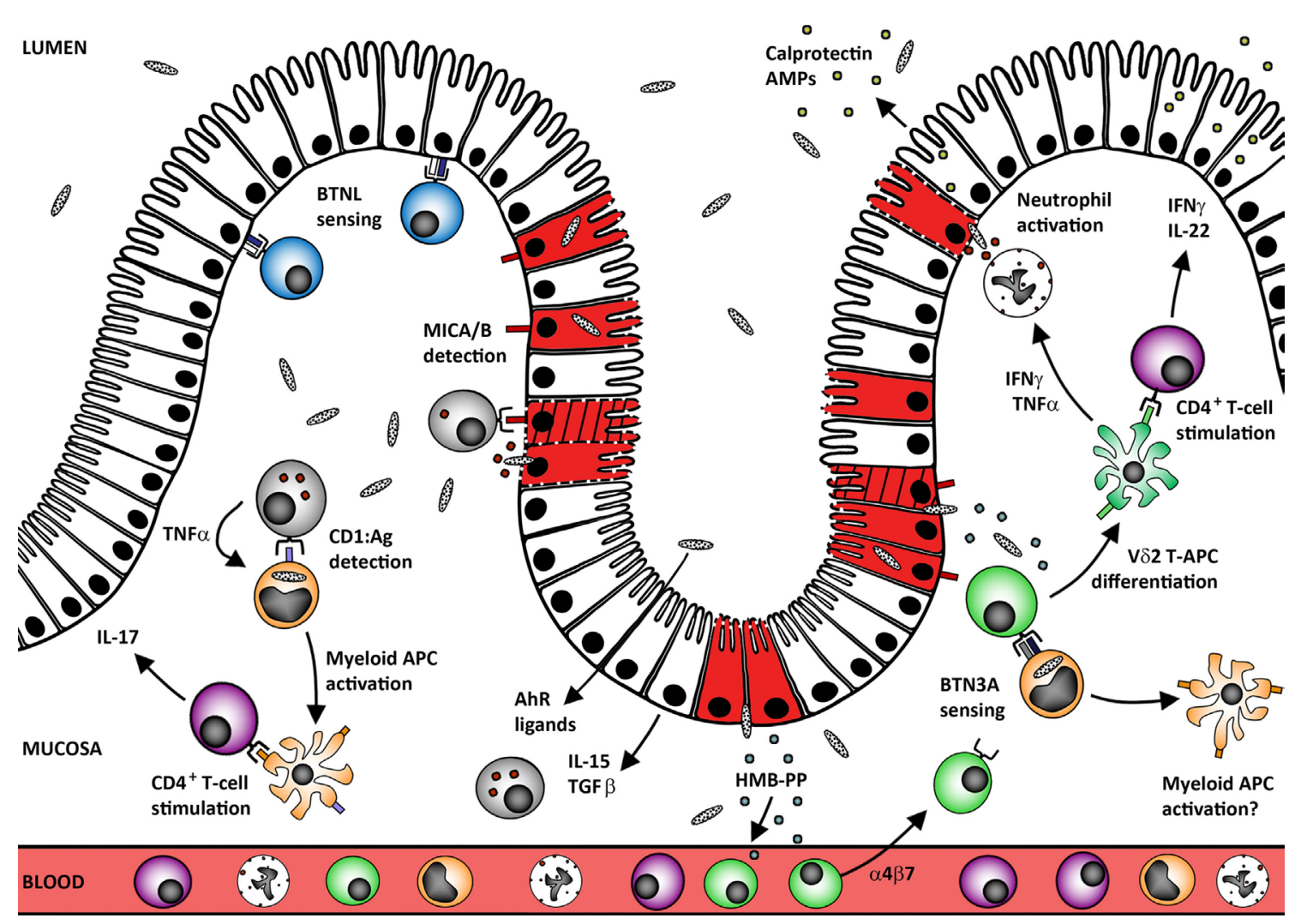

FIGURE 1 | Human mucosal $\gamma \delta$ T-cells protect the epithelial barrier against microbes and tumors. Tissue-resident $\gamma \delta$ T-cells may develop in situ under the control of site-specific BTNL heterodimers that maintain these cells in a primed but inactivate state (blue V $\delta 1^{+}$cells). Human mucosal barrier sites are also enriched in CD1+ myeloid APC (orange cells) that capture microbes and may undergo local TNF-induced maturation via self-antigen presentation to CD1-restricted $\gamma \delta$ T-cells. The resultant mature APC can stimulate conventional $\alpha \beta$ T-cell responses at the site of infection without the need to migrate through the draining lymphatics. Loss of BTNL signaling or upregulation of MICA/B expression by the infected/transformed/stressed epithelium (red/hatched/membrane-damaged cells) also triggers $\gamma \delta$ T-cell cytotoxic responses that rapidly lyse the compromised cells (gray cells; both V $\delta 1^{+}$and V $\delta 2^{+}$subsets). Maintenance of these "epithelial surveillance" $\gamma \delta$ T-cell populations is regulated by a complex variety of signals including local provision of AhR ligands, epithelial cytokine IL-15, and growth factor TGF- $\beta$. These factors likely also play critical roles in promoting tissue residence of recruited $\gamma \delta$ T-cell populations. In the case of V $\delta 2^{+} \mathrm{T}$-cells (green cells), recruitment from the blood could be driven by (E)-4-hydroxy-3-methyl-but-2-enyl pyrophosphate (HMB-PP) translocation across the defective mucosal barrier. Accumulation of microbial HMB-PP in the mucosa can then trigger BTN3A-mediated activation of $\mathrm{V} \delta 2^{+} \mathrm{T}$-cells in the presence of IL-15 to promote differentiation into potent APC (and perhaps also reciprocal activation of local myeloid cell populations). This process supports rapid local generation of presenting cells that can stimulate CD4+ $4^{+}$-cell expression of barrier protectant cytokines, including IFN $\gamma$ and IL-22 (purple CD4+ T-cells). These mediators promote epithelial release of antimicrobial peptides (AMPs) including calprotectin and cooperate with $\mathrm{TNF} \alpha$ to promote neutrophil activation and survival. 


\section{FUTURE CONSIDERATIONS FOR THERAPEUTIC TARGETING OF MUCOSAL $\gamma \delta$ T-CELLS}

Human $\gamma \delta$ T-cells display potent effector functions when exposed to microbial antigens and/or host molecules commonly encountered at barrier sites, but accumulating evidence suggests an additional ability to modulate downstream mucosal leukocyte responses (Figure 1). These features may be shared by multiple $\gamma \delta$ T-cell subsets in human tissues, since even the little-studied $\mathrm{V} \delta 3^{+}$subset appears capable of complex patterns of cytokine expression and promoting DC maturation mediated by CD1/ TNF $\alpha$ (76). Together, these data suggest that tissue-resident $\gamma \delta$ T-cells play important roles in activating host immunity to microbes across multiple mucosal sites, not just the lung and intestine. Indeed, recent findings indicate that commensals residing in the ocular mucosa can induce $\gamma \delta$ T-cell expression of IL-17 to drive neutrophil recruitment and protect the mouse eye against bacterial and fungal pathogens (77). Human $\gamma \delta$ T-cells in mucosal tissues may be similarly specialized to detect local microbial and host stress molecules and respond not only with rapid effector functions, but also by relaying critical information to other mucosal leukocyte populations. Data from our own laboratories indicate that human $\mathrm{V} \delta 2^{+} \mathrm{T}$-cells can significantly modify intestinal immune responses via direct antigen presentation in vitro (72), and influence the clinical outcome of microbial infections in vivo (39), hence these cells should be a high priority for the development of novel immunotherapies. Indeed, a recent transcriptome analysis of 585 human colorectal cancer samples revealed that tumor infiltration by IFN $\gamma$-producing $\mathrm{V} \delta 2^{+} \mathrm{T}$-cells in particular was associated with higher probability of 5-year disease-free survival (78). Given that $\gamma \delta$ T-cells also exhibit potent activity in non-malignant settings, it seems likely that therapies targeting these cells could prove effective in a range of different pathologies. Multiple drugs already in widespread clinical use likely owe their therapeutic efficacy in part to modulation of $\gamma \delta$ T-cell function, including the anti- $\alpha 4 \beta 7$ antibody vedolizumab

\section{REFERENCES}

1. Gentles AJ, Newman AM, Liu CL, Bratman SV, Feng W, Kim D, et al. The prognostic landscape of genes and infiltrating immune cells across human cancers. Nat Med (2015) 21:938-45. doi:10.1038/nm.3909

2. Pauza CD, Cairo C. Evolution and function of the TCR Vgamma9 chain repertoire: it's good to be public. Cell Immunol (2015) 296:22-30. doi:10.1016/j. cellimm.2015.02.010

3. Swamy M, Jamora C, Havran W, Hayday A. Epithelial decision makers: in search of the 'epimmunome'. Nat Immunol (2010) 11:656-65. doi:10.1038/ ni. 1905

4. Guy-Grand D, Vassalli P, Eberl G, Pereira P, Burlen-Defranoux O, Lemaitre F, et al. Origin, trafficking, and intraepithelial fate of gut-tropic T cells. J Exp Med (2013) 210:1839-54. doi:10.1084/jem.20122588

5. DiMarco BarrosR, Roberts NA, DartRJ, VantouroutP, JandkeA, NussbaumerO, et al. Epithelia use butyrophilin-like molecules to shape organ-specific gammadelta T cell compartments. Cell (2016) 167:203-218 e17. doi:10.1016/j. cell.2016.08.030

6. Holtmeier W, Witthoft T, Hennemann A, Winter HS, Kagnoff MF. The TCRdelta repertoire in human intestine undergoes characteristic changes during fetal to adult development. J Immunol (1997) 158:5632-41.
(79-81), anti-TNF agents including infliximab $(38,82-85)$, and immunosuppressant drug azathioprine (86). The aminobisphosphonate drug zoledronate has also been shown to promote $\mathrm{V} \delta 2^{+}$ T-cell activation in vivo by inhibiting the farnesyl pyrophosphate synthase enzyme to allow host cell accumulation of isopentenylpyrophosphate (87). Work is ongoing to identify optimal strategies for zoledronate adjunctive therapy, which has so far displayed variable patient benefit in clinical trials $(88,89)$. However, the continuing development of aminobisphosphonate pro-drugs and $\gamma \delta$-selective nanobody agonists/antagonists will soon yield more potent therapies for a variety of major human disorders (90-92). Given that $\gamma \delta$ T-cell biology is closely associated with epithelial barriers, a key consideration for future treatment strategies will be ensuring the effective targeting of $\gamma \delta$ T-cells to tissues of interest $(55,58,93,94)$. Limiting $\gamma \delta$ T-cell egress from the blood may prove beneficial when treating blood malignancies and mucosal inflammatory disorders such as IBD (e.g., with anti-integrin antibodies), whereas enhancing cell migration to barrier sites will likely be key to enhancing protection against mucosal infection and epithelial tumors. The extent to which therapeutic outcomes are influenced by the mechanisms that promote $\gamma \delta \mathrm{T}$-cell tissue residency will also need to be explored.

\section{AUTHOR CONTRIBUTIONS}

NM and ME drafted the manuscript, revised the content, and approved the final version.

\section{ACKNOWLEDGMENTS}

The authors thank the members of our research teams for their contributions. The authors are also grateful to Nital Sumaria and Stefania Martin for helpful suggestions. This work was supported by the Wellcome Trust Institutional Strategic Support Fund, Crohn's and Colitis UK, Crohn's in Childhood Research Association, and the Medical Research Council (MR/N023145/1) (MR/R008302/1).

7. Rhodes DA, Reith W, Trowsdale J. Regulation of immunity by butyrophilins. Annu Rev Immunol (2016) 34:151-72. doi:10.1146/annurev-immunol-041015055435

8. Li Y, Innocentin S, Withers DR, Roberts NA, Gallagher AR, Grigorieva EF, et al. Exogenous stimuli maintain intraepithelial lymphocytes via aryl hydrocarbon receptor activation. Cell (2011) 147:629-40. doi:10.1016/j.cell.2011.09.025

9. Sugahara S, Shimizu T, Yoshida Y, Aiba T, Yamagiwa S, Asakura H, et al. Extrathymic derivation of gut lymphocytes in parabiotic mice. Immunology (1999) 96:57-65. doi:10.1046/j.1365-2567.1999.00665.x

10. Munoz-Ruiz M, Sumaria N, Pennington DJ, Silva-Santos B. Thymic determinants of gammadelta T cell differentiation. Trends Immunol (2017) 38:336-44. doi:10.1016/j.it.2017.01.007

11. Papotto PH, Reinhardt A, Prinz I, Silva-Santos B. Innately versatile: gammadelta17 $\mathrm{T}$ cells in inflammatory and autoimmune diseases. J Autoimmun (2017) 87:26-37. doi:10.1016/j.jaut.2017.11.006

12. Arnett HA, Escobar SS, Gonzalez-Suarez E, Budelsky AL, Steffen LA, Boiani N, et al. BTNL2, a butyrophilin/B7-like molecule, is a negative costimulatory molecule modulated in intestinal inflammation. J Immunol (2007) 178:152333. doi:10.4049/jimmunol.178.3.1523

13. Prescott NJ, Lehne B, Stone K, Lee JC, Taylor K, Knight J, et al. Pooled sequencing of 531 genes in inflammatory bowel disease identifies an associated rare 
variant in BTNL2 and implicates other immune related genes. PLoS Genet (2015) 11:e1004955. doi:10.1371/journal.pgen.1004955

14. Edelblum KL, Shen L, Weber CR, Marchiando AM, Clay BS, Wang Y, et al. Dynamic migration of gammadelta intraepithelial lymphocytes requires occludin. Proc Natl Acad Sci U S A (2012) 109:7097-102. doi:10.1073/pnas. 1112519109

15. Hoytema van Konijnenburg DP, Reis BS, Pedicord VA, Farache J, Victora GD, Mucida D. Intestinal epithelial and intraepithelial T cell crosstalk mediates a dynamic response to infection. Cell (2017) 171:783-794 e13. doi:10.1016/j. cell.2017.08.046

16. Bandeira A, Mota-Santos T, Itohara S, Degermann S, Heusser C, Tonegawa S, et al. Localization of gamma/delta $\mathrm{T}$ cells to the intestinal epithelium is independent of normal microbial colonization. J Exp Med (1990) 172:239-44. doi:10.1084/jem.172.1.239

17. Ismail AS, Severson KM, Vaishnava S, Behrendt CL, Yu X, Benjamin JL, et al. Gammadelta intraepithelial lymphocytes are essential mediators of hostmicrobial homeostasis at the intestinal mucosal surface. Proc Natl Acad Sci US A (2011) 108:8743-8. doi:10.1073/pnas.1019574108

18. Groh V, Bahram S, Bauer S, Herman A, Beauchamp M, Spies T. Cell stressregulated human major histocompatibility complex class I gene expressed in gastrointestinal epithelium. Proc Natl Acad Sci U S A (1996) 93:12445-50. doi:10.1073/pnas.93.22.12445

19. Groh V, Steinle A, Bauer S, Spies T. Recognition of stress-induced MHC molecules by intestinal epithelial gammadelta T cells. Science (1998) 279:1737-40. doi:10.1126/science.279.5357.1737

20. Groh V, Rhinehart R, Secrist H, Bauer S, Grabstein KH, Spies T. Broad tumor-associated expression and recognition by tumor-derived gamma delta T cells of MICA and MICB. Proc Natl Acad Sci U S A (1999) 96:6879-84. doi:10.1073/pnas.96.12.6879

21. Zocchi MR, Ferrarini M, Rugarli C. Selective lysis of the autologous tumor by delta TCS1+ gamma/delta+ tumor-infiltrating lymphocytes from human lung carcinomas. Eur J Immunol (1990) 20:2685-9. doi:10.1002/eji. 1830201224

22. Halary F, Pitard V, Dlubek D, Krzysiek R, de la Salle H, Merville P, et al. Shared reactivity of $\mathrm{V}\{$ delta\}2(neg) \{gamma\}\{delta\} T cells against cytomegalovirus-infected cells and tumor intestinal epithelial cells. J Exp Med (2005) 201:1567-78. doi:10.1084/jem.20041851

23. Bauer S, Groh V, Wu J, Steinle A, Phillips JH, Lanier LL, et al. Activation of NK cells and T cells by NKG2D, a receptor for stress-inducible MICA. Science (1999) 285:727-9. doi:10.1126/science.285.5428.727

24. Meresse B, Chen Z, Ciszewski C, Tretiakova M, Bhagat G, Krausz TN, et al. Coordinated induction by IL15 of a TCR-independent NKG2D signaling pathway converts CTL into lymphokine-activated killer cells in celiac disease. Immunity (2004) 21:357-66. doi:10.1016/j.immuni.2004.06.020

25. Yu Q, Tang C, Xun S, Yajima T, Takeda K, Yoshikai Y. MyD88-dependent signaling for IL-15 production plays an important role in maintenance of CD8 alpha alpha TCR alpha beta and TCR gamma delta intestinal intraepithelial lymphocytes. J Immunol (2006) 176:6180-5. doi:10.4049/jimmunol.176.10.6180

26. Zhao $\mathrm{H}$, Nguyen $\mathrm{H}$, Kang J. Interleukin 15 controls the generation of the restricted $\mathrm{T}$ cell receptor repertoire of gamma delta intestinal intraepithelial lymphocytes. Nat Immunol (2005) 6:1263-71. doi:10.1038/ni1267

27. Inagaki-Ohara K, Chinen T, Matsuzaki G, Sasaki A, Sakamoto Y, Hiromatsu K, et al. Mucosal T cells bearing TCRgammadelta play a protective role in intestinal inflammation. J Immunol (2004) 173:1390-8. doi:10.4049/jimmunol. 173.2 .1390

28. McVay LD, Li B, Biancaniello R, Creighton MA, Bachwich D, Lichtenstein G, et al. Changes in human mucosal gamma delta $\mathrm{T}$ cell repertoire and function associated with the disease process in inflammatory bowel disease. Mol Med (1997) 3:183-203.

29. Holtmeier W, Rowell DL, Nyberg A, Kagnoff MF. Distinct delta T cell receptor repertoires in monozygotic twins concordant for coeliac disease. Clin Exp Immunol (1997) 107:148-57. doi:10.1046/j.1365-2249.1997.d01-887.x

30. Maiuri L, Ciacci C, Auricchio S, Brown V, Quaratino S, Londei M. Interleukin 15 mediates epithelial changes in celiac disease. Gastroenterology (2000) 119:996-1006. doi:10.1053/gast.2000.18149

31. Jabri B, Sollid LM. Tissue-mediated control of immunopathology in coeliac disease. Nat Rev Immunol (2009) 9:858-70. doi:10.1038/nri2670

32. Liu Z, Geboes K, Colpaert S, D’Haens GR, Rutgeerts P, Ceuppens JL. IL-15 is highly expressed in inflammatory bowel disease and regulates local
T cell-dependent cytokine production. JImmunol (2000) 164:3608-15. doi:10.4049/jimmunol.164.7.3608

33. Bhagat G, Naiyer AJ, Shah JG, Harper J, Jabri B, Wang TC, et al. Small intestinal CD8+TCRgammadelta+NKG2A+ intraepithelial lymphocytes have attributes of regulatory cells in patients with celiac disease. J Clin Invest (2008) 118:281-93. doi:10.1172/JCI30989

34. Kuhl AA, Pawlowski NN, Grollich K, Loddenkemper C, Zeitz M, Hoffmann JC. Aggravation of intestinal inflammation by depletion/deficiency of gammadelta T cells in different types of IBD animal models. J Leukoc Biol (2007) 81:168-75. doi:10.1189/jlb.1105696

35. Leslie DS, Vincent MS, Spada FM, Das H, Sugita M, Morita CT, et al. CD1-mediated gamma/delta T cell maturation of dendritic cells. J Exp Med (2002) 196:1575-84. doi:10.1084/jem.20021515

36. McCarthy NE, Jones HA, Marks NA, Shiner RJ, Ind PW, Al-Hassi HO, et al. Inhaled allergen-driven CD1c up-regulation and enhanced antigen uptake by activated human respiratory-tract dendritic cells in atopic asthma. Clin Exp Allergy (2007) 37:72-82. doi:10.1111/j.1365-2222.2006.02631.x

37. Lahn M, Kalataradi H, Mittelstadt P, Pflum E, Vollmer M, Cady C, et al. Early preferential stimulation of gamma delta $\mathrm{T}$ cells by TNF-alpha. J Immunol (1998) 160:5221-30.

38. Li H, Luo K, Pauza CD. TNF-alpha is a positive regulatory factor for human Vgamma2 Vdelta2 T cells. J Immunol (2008) 181:7131-7. doi:10.4049/jimmunol. 181.10 .7131

39. Davey MS, Lin CY, Roberts GW, Heuston S, Brown AC, Chess JA, et al. Human neutrophil clearance of bacterial pathogens triggers anti-microbial gammadelta T cell responses in early infection. PLoS Pathog (2011) 7:e1002040. doi:10.1371/journal.ppat.1002040

40. Sporri R, Reis e Sousa C. Inflammatory mediators are insufficient for full dendritic cell activation and promote expansion of CD4+ T cell populations lacking helper function. Nat Immunol (2005) 6:163-70. doi:10.1038/ni1162

41. Munz C, Steinman RM, Fujii S. Dendritic cell maturation by innate lymphocytes: coordinated stimulation of innate and adaptive immunity. J Exp Med (2005) 202:203-7. doi:10.1084/jem.20050810

42. Tangri S, Brossay L, Burdin N, Lee DJ, Corr M, Kronenberg M. Presentation of peptide antigens by mouse $\mathrm{CD} 1$ requires endosomal localization and protein antigen processing. Proc Natl Acad Sci U S A (1998) 95:14314-9. doi:10.1073/ pnas.95.24.14314

43. De Libero G, Moran AP, Gober HJ, Rossy E, Shamshiev A, Chelnokova O, et al. Bacterial infections promote $\mathrm{T}$ cell recognition of self-glycolipids. Immunity (2005) 22:763-72. doi:10.1016/j.immuni.2005.04.013

44. Agea E, Russano A, Bistoni O, Mannucci R, Nicoletti I, Corazzi L, et al. Human CD1-restricted T cell recognition of lipids from pollens. J Exp Med (2005) 202:295-308. doi:10.1084/jem.20050773

45. Wenzel S, Holgate ST. The mouse trap: it still yields few answers in asthma. Am J Respir Crit Care Med (2006) 174:1173-6; discussion 1176-8. doi:10.1164/ rccm. 2609002

46. Cui ZH, Joetham A, Aydintug MK, Hahn YS, Born WK, Gelfand EW. Reversal of allergic airway hyperreactivity after long-term allergen challenge depends on gammadelta T cells. Am J Respir Crit Care Med (2003) 168:1324-32. doi:10.1164/rccm.200305-634OC

47. McMenamin C, Pimm C, McKersey M, Holt PG. Regulation of IgE responses to inhaled antigen in mice by antigen-specific gamma delta $\mathrm{T}$ cells. Science (1994) 265:1869-71. doi:10.1126/science.7916481

48. Do JS, Visperas A, Dong C, Baldwin WM III, Min B. Cutting Edge: generation of colitogenic Th17 CD4 T cells is enhanced by IL-17+ \{gamma $\}$ delta $\}$ T cells. J Immunol (2011) 186:4546-50. doi:10.4049/jimmunol.1004021

49. Do JS, Kim S, Keslar K, Jang E, Huang E, Fairchild RL, et al. gammadelta T cells coexpressing gut homing alpha4beta7 and alphaE integrins define a novel subset promoting intestinal inflammation. JImmunol (2017) 198:908-15. doi:10.4049/jimmunol.1601060

50. Cheung AKL, Kwok HY, Huang Y, Chen M, Mo Y, Wu X, et al. Gut-homing Delta42PD1(+)Vdelta2 $\mathrm{T}$ cells promote innate mucosal damage via TLR4 during acute HIV type 1 infection. Nat Microbiol (2017) 2:1389-402. doi:10.1038/s41564-017-0006-5

51. Godfrey DI, Uldrich AP, McCluskey J, Rossjohn J, Moody DB. The burgeoning family of unconventional T cells. Nat Immunol (2015) 16:1114-23. doi:10.1038/ni.3298

52. Morita CT, Jin C, Sarikonda G, Wang H. Nonpeptide antigens, presentation mechanisms, and immunological memory of human Vgamma2Vdelta2 
T cells: discriminating friend from foe through the recognition of prenyl pyrophosphate antigens. Immunol Rev (2007) 215:59-76. doi:10.1111/ j.1600-065X.2006.00479.x

53. Liuzzi AR, McLaren JE, Price DA, Eberl M. Early innate responses to pathogens: pattern recognition by unconventional human T-cells. Curr Opin Immunol (2015) 36:31-7. doi:10.1016/j.coi.2015.06.002

54. Laggner U, Di Meglio P, Perera GK, Hundhausen C, Lacy KE, Ali N, et al. Identification of a novel proinflammatory human skin-homing Vgamma9Vdelta2 $\mathrm{T}$ cell subset with a potential role in psoriasis. J Immunol (2011) 187:2783-93. doi:10.4049/jimmunol.1100804

55. McCarthy NE, Bashir Z, Vossenkamper A, Hedin CR, Giles EM, Bhattacharjee S, et al. Proinflammatory Vdelta2 $+\mathrm{T}$ cells populate the human intestinal mucosa and enhance IFN-gamma production by colonic alphabeta T cells. J Immunol (2013) 191:2752-63. doi:10.4049/jimmunol.1202959

56. Eberl M, Hintz M, Reichenberg A, Kollas AK, Wiesner J, Jomaa H. Microbial isoprenoid biosynthesis and human gammadelta $\mathrm{T}$ cell activation. FEBS Lett (2003) 544:4-10. doi:10.1016/S0014-5793(03)00483-6

57. Scheper W, Sebestyen Z, Kuball J. Cancer immunotherapy using $\gamma \delta \mathrm{T}$ cells: dealing with diversity. Front Immunol (2014) 5:601. doi:10.3389/ fimmu.2014.00601

58. Brandes M, Willimann K, Lang AB, Nam KH, Jin C, Brenner MB, et al. Flexible migration program regulates gamma delta T-cell involvement in humoral immunity. Blood (2003) 102:3693-701. doi:10.1182/blood-2003-04-1016

59. Ali Z, Shao L, Halliday L, Reichenberg A, Hintz M, Jomaa H, et al. Prolonged (E)-4-hydroxy-3-methyl-but-2-enyl pyrophosphate-driven antimicrobial and cytotoxic responses of pulmonary and systemic Vgamma2Vdelta2 T cells in macaques. J Immunol (2007) 179:8287-96. doi:10.4049/jimmunol.179.12. 8287

60. Ryan-Payseur B, Frencher J, Shen L, Chen CY, Huang D, Chen ZW. Multieffectorfunctional immune responses of HMBPP-specific Vgamma2Vdelta2 T cells in nonhuman primates inoculated with Listeria monocytogenes $\{$ Delta\}actA

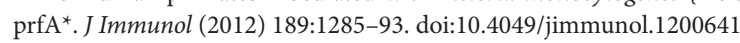

61. Wang L, Kamath A, Das H, Li L, Bukowski JF. Antibacterial effect of human $\mathrm{V}$ gamma $2 \mathrm{~V}$ delta $2 \mathrm{~T}$ cells in vivo. JClin Invest (2001) 108:1349-57. doi:10.1172/JCI200113584

62. Huang D, Chen CY, Ali Z, Shao L, Shen L, Lockman HA, et al. Antigen-specific Vgamma2Vdelta2 $\mathrm{T}$ effector cells confer homeostatic protection against pneumonic plaque lesions. Proc Natl Acad Sci U S A (2009) 106:7553-8. doi:10.1073/pnas.0811250106

63. Chen CY, Yao S, Huang D, Wei H, Sicard H, Zeng G, et al. Phosphoantigen/IL2 expansion and differentiation of Vgamma2Vdelta2 $\mathrm{T}$ cells increase resistance to tuberculosis in nonhuman primates. PLoS Pathog (2013) 9:e1003501. doi:10.1371/journal.ppat.1003501

64. Mackay LK, Kallies A. Transcriptional regulation of tissue-resident lymphocytes. Trends Immunol (2017) 38:94-103. doi:10.1016/j.it.2016.11.004

65. Mackay LK, Rahimpour A, Ma JZ, Collins N, Stock AT, Hafon ML, et al. The developmental pathway for $\mathrm{CD} 103(+) \mathrm{CD} 8+$ tissue-resident memory T cells of skin. Nat Immunol (2013) 14:1294-301. doi:10.1038/ni.2744

66. Conti L, Casetti R, Cardone M, Varano B, Martino A, Belardelli F, et al. Reciprocal activating interaction between dendritic cells and pamidronate-stimulated gammadelta T cells: role of CD86 and inflammatory cytokines. J Immunol (2005) 174:252-60. doi:10.4049/jimmunol.174.1.252

67. Eberl M, Roberts GW, Meuter S, Williams JD, Topley N, Moser B. A rapid crosstalk of human gammadelta $\mathrm{T}$ cells and monocytes drives the acute inflammation in bacterial infections. PLoS Pathog (2009) 5:e1000308. doi:10.1371/journal.ppat.1000308

68. Brandes M, Willimann K, Moser B. Professional antigen-presentation function by human gammadelta T Cells. Science (2005) 309:264-8. doi:10.1126/ science. 1110267

69. Wu Y, Wu W, Wong WM, Ward E, Thrasher AJ, Goldblatt D, et al. Human gamma delta T cells: a lymphoid lineage cell capable of professional phagocytosis. JImmunol (2009) 183:5622-9. doi:10.4049/jimmunol. 0901772

70. Hintz M, Reichenberg A, Altincicek B, Bahr U, Gschwind RM, Kollas AK, et al. Identification of (E)-4-hydroxy-3-methyl-but-2-enyl pyrophosphate as a major activator for human gammadelta $\mathrm{T}$ cells in Escherichia coli. FEBS Lett (2001) 509:317-22. doi:10.1016/S0014-5793(01)03191-X

71. Breese EJ, Michie CA, Nicholls SW, Murch SH, Williams CB, Domizio P, et al. Tumor necrosis factor alpha-producing cells in the intestinal mucosa of children with inflammatory bowel disease. Gastroenterology (1994) 106: 1455-66. doi:10.1016/0016-5085(94)90398-0

72. Tyler CJ, McCarthy NE, Lindsay JO, Stagg AJ, Moser B, Eberl M. Antigenpresenting human gammadelta $\mathrm{T}$ cells promote intestinal $\mathrm{CD} 4+\mathrm{T}$ cell expression of IL-22 and mucosal release of calprotectin. J Immunol (2017) 198:3417-25. doi:10.4049/jimmunol.1700003

73. Ohnmacht C, Marques R, Presley L, Sawa S, Lochner M, Eberl G. Intestinal microbiota, evolution of the immune system and the bad reputation of pro-inflammatory immunity. Cell Microbiol (2011) 13:653-9. doi:10.1111/j.1462-5822.2011.01577.x

74. Hueber W, Sands BE, Lewitzky S, Vandemeulebroecke M, Reinisch W, Higgins PD, et al. Secukinumab, a human anti-IL-17A monoclonal antibody, for moderate to severe Crohn's disease: unexpected results of a randomised, double-blind placebo-controlled trial. Gut (2012) 61:1693-700. doi:10.1136/ gutjnl-2011-301668

75. Targan SR, Feagan B, Vermeire S, Panaccione R, Melmed GY, Landers C, et al. A randomized, double-blind, placebo-controlled phase 2 study of brodalumab in patients with moderate-to-severe Crohn's disease. Am J Gastroenterol (2016) 111:1599-607. doi:10.1038/ajg.2016.298

76. Mangan BA, Dunne MR, O'Reilly VP, Dunne PJ, Exley MA, O'Shea D, et al. Cutting edge: CD1d restriction and Th1/Th2/Th17 cytokine secretion by human Vdelta3 T cells. J Immunol (2013) 191:30-4. doi:10.4049/jimmunol. 1300121

77. St Leger AJ, Desai JV, Drummond RA, Kugadas A, Almaghrabi F, Silver P, et al. An Ocular commensal protects against corneal infection by driving an interleukin-17 response from mucosal gammadelta T cells. Immunity (2017) 47:148-158 e5. doi:10.1016/j.immuni.2017.06.014

78. Meraviglia S, Lo Presti E, Tosolini M, La Mendola C, Orlando V, Todaro M, et al. Distinctive features of tumor-infiltrating gammadelta $\mathrm{T}$ lymphocytes in human colorectal cancer. Oncoimmunology (2017) 6:e1347742. doi:10.1080/ 2162402X.2017.1347742

79. Fedyk ER, Wyant T, Yang LL, Csizmadia V, Burke K, Yang H, et al. Exclusive antagonism of the alpha4 beta7 integrin by vedolizumab confirms the gutselectivity of this pathway in primates. Inflamm Bowel Dis (2012) 18:2107-19. doi:10.1002/ibd.22940

80. Fuchs F, Schillinger D, Atreya R, Hirschmann S, Fischer S, Neufert C, et al. Clinical response to vedolizumab in ulcerative colitis patients is associated with changes in integrin expression profiles. Front Immunol (2017) 8:764. doi:10.3389/fimmu.2017.00764

81. Dart RJ, Samaan MA, Powell N, Irving PM. Vedolizumab: toward a personalized therapy paradigm for people with ulcerative colitis. Clin Exp Gastroenterol (2017) 10:57-66. doi:10.2147/CEG.S110547

82. Biancheri P, Di Sabatino A, Rovedatti L, Giuffrida P, Calarota SA, Vetrano S, et al. Effect of tumor necrosis factor-alpha blockade on mucosal addressin cell-adhesion molecule-1 in Crohn's disease. Inflamm Bowel Dis (2013) 19:259-64. doi:10.1097/MIB.0b013e31828100a4

83. ten Hove T, van Montfrans C, Peppelenbosch MP, van Deventer SJ. Infliximab treatment induces apoptosis of lamina propria T lymphocytes in Crohn's disease. Gut (2002) 50:206-11. doi:10.1136/gut.50.2.206

84. Kelsen J, Dige A, Schwindt H, D’Amore F, Pedersen FS, Agnholt J, et al. Infliximab induces clonal expansion of gammadelta-T cells in Crohn's disease: a predictor of lymphoma risk? PLoS One (2011) 6:e17890. doi:10.1371/ journal.pone. 0017890

85. Accardo-Palumbo A, Giardina AR, Ciccia F, Ferrante A, Principato A, Impastato R, et al. Phenotype and functional changes of Vgamma9/Vdelta2 T lymphocytes in Behcet's disease and the effect of infliximab on Vgamma9/ Vdelta2 $\mathrm{T}$ cell expansion, activation and cytotoxicity. Arthritis Res Ther (2010) 12:R109. doi:10.1186/ar3043

86. McCarthy NE, Hedin CR, Sanders TJ, Amon P, Hoti I, Ayada I, et al. Azathioprine therapy selectively ablates human Vdelta2(+) T cells in Crohn's disease. J Clin Invest (2015) 125:3215-25. doi:10.1172/JCI80840

87. Roelofs AJ, Jauhiainen M, Mönkkönen H, Rogers MJ, Mönkkönen J, Thompson K. Peripheral blood monocytes are responsible for gammadelta $\mathrm{T}$ cell activation induced by zoledronic acid through accumulation of IPP/ DMAPP. Br J Haematol (2009) 144(2):245-50. doi:10.1111/j.1365-2141. 2008.07435.x

88. Lo Presti E, Pizzolato G, Gulotta E, Cocorullo G, Gulotta G, Dieli F, et al. Current advances in gammadelta $\mathrm{T}$ cell-based tumor immunotherapy. Front Immunol (2017) 8:1401. doi:10.3389/fimmu.2017.01401 
89. Fournie JJ, Sicard H, Poupot M, Bezombes C, Blanc A, Romagne F, et al. What lessons can be learned from gammadelta $\mathrm{T}$ cell-based cancer immunotherapy trials? Cell Mol Immunol (2013) 10:35-41. doi:10.1038/cmi.2012.39

90. Tanaka Y, Iwasaki M, Murata-Hirai K, Matsumoto K, Hayashi K, Okamura H, et al. Anti-tumor activity and immunotherapeutic potential of a bisphosphonate prodrug. Sci Rep (2017) 7:5987. doi:10.1038/s41598-017-05553-0

91. de Bruin RC, Stam AG, Vangone A, van Bergen En Henegouwen PM, Verheul HM, Sebestyen Z, et al. Prevention of Vgamma9Vdelta2 T cell activation by a Vgamma9Vdelta2 TCR nanobody. J Immunol (2017) 198:308-17. doi:10.4049/jimmunol.1600948

92. Davey MS, Malde R, Mykura RC, Baker AT, Taher TE, Le Duff CS, et al. Synthesis and biological evaluation of (E)-4-hydroxy-3-methylbut-2-enyl phosphate (HMBP) aryloxy triester phosphoramidate prodrugs as activators of Vgamma9/Vdelta2 T-cell immune responses. JMed Chem (2018) 61:2111-7. doi:10.1021/acs.jmedchem.7b01824

93. Mann ER, McCarthy NE, Peake ST, Milestone AN, Al-Hassi HO, Bernardo D, et al. Skin- and gut-homing molecules on human circulating gammadelta $\mathrm{T}$ cells and their dysregulation in inflammatory bowel disease. Clin Exp Immunol (2012) 170:122-30. doi:10.1111/j.1365-2249.2012.04649.x

94. McKenzie DR, Kara EE, Bastow CR, Tyllis TS, Fenix KA, Gregor CE, et al IL-17-producing gammadelta $\mathrm{T}$ cells switch migratory patterns between resting and activated states. Nat Commun (2017) 8:15632. doi:10.1038/ ncomms 15632

Conflict of Interest Statement: The authors declare that the research was conducted in the absence of any commercial or financial relationships that could be construed as a potential conflict of interest.

Copyright (C) 2018 McCarthy and Eberl. This is an open-access article distributed under the terms of the Creative Commons Attribution License (CC BY). The use, distribution or reproduction in other forums is permitted, provided the original author(s) and the copyright owner are credited and that the original publication in this journal is cited, in accordance with accepted academic practice. No use, distribution or reproduction is permitted which does not comply with these terms. 